\title{
Quantitative analysis of histone exchange for transcriptionally active chromatin
}

Stephanie D Byrum ${ }^{1}$, Sean D Taverna ${ }^{2+}$ and Alan J Tackett ${ }^{1^{*}}$

\begin{abstract}
Background: Genome-wide studies use techniques, like chromatin immunoprecipitation, to purify small chromatin sections so that protein-protein and protein-DNA interactions can be analyzed for their roles in modulating gene transcription. Histone post-translational modifications (PTMs) are key regulators of gene transcription and are therefore prime targets for these types of studies. Chromatin purification protocols vary in the amount of chemical cross-linking used to preserve in vivo interactions. A balanced level of chemical cross-linking is required to preserve the native chromatin state during purification, while still allowing for solubility and interaction with affinity reagents.

Findings: We previously used an isotopic labeling technique combining affinity purification and mass spectrometry called transient isotopic differentiation of interactions as random or targeted (transient I-DIRT) to identify the amounts of chemical cross-linking required to prevent histone exchange during chromatin purification. New bioinformatic analyses reported here reveal that histones containing transcription activating PTMs exchange more rapidly relative to bulk histones and therefore require a higher level of cross-linking to preserve the in vivo chromatin structure.

Conclusions: The bioinformatic approach described here is widely applicable to other studies requiring the analysis and purification of cognate histones and their modifications. Histones containing PTMs correlated to active gene transcription exchange more readily than bulk histones; therefore, it is necessary to use more rigorous in vivo chemical cross-linking to stabilize these marks during chromatin purification.
\end{abstract}

Keywords: cross-linking, histone, post-translational modification, chromatin, affinity purification

\section{Introduction}

Eukaryotic genomes are highly organized into transcriptionally active (euchromatic) and silent (heterochromatic) chromatin regions. Conversion of chromatin between the two major forms is regulated in part through interactions between chromatin-modifying enzymes and nucleosomes. Nucleosomes are the fundamental unit of chromatin and consist of approximately 147 base pairs of DNA wrapped around an octameric core of the histones H2A, H2B, H3, and H4 [1]. Chromatin structure plays a key role in the regulation of gene activity and its mis-regulation is a theme characteristic of many types of disease and cancer [1]. The N-

\footnotetext{
* Correspondence: ajtackett@uams.edu

† Contributed equally

'University of Arkansas for Medical Sciences, 4301 West Markham Street,

Little Rock, Arkansas 72205, USA

Full list of author information is available at the end of the article
}

terminal tails of histones, which protrude outside of the nucleosome core [2], are subject to many sites and types of post-translational modifications (PTMs), which, in turn, help regulate biological processes through altering nucleosome stability or the function of chromatin-associated complexes $[3,4]$. For example, acetylation of histone lysine residues on the N-terminal tail has been correlated to active gene transcription either by countering the negative charge of the DNA backbone, or through the recruitment or stabilization of bromodomain-containing proteins $[3,5,6]$.

A major emphasis in the field of chromatin biology is the understanding of how histone PTMs and proteinprotein interactions are associated with specific gene loci to regulate gene transcription. Current technologies like ChIP (chromatin immunoprecipitation), affinity purification of protein-histone complexes for proteomic analysis, and more recent technology that allows for the
C Biomed Central

() 2011 Byrum et al; licensee BioMed Central Ltd. This is an Open Access article distributed under the terms of the Creative Commons Attribution License (http://creativecommons.org/licenses/by/2.0), which permits unrestricted use, distribution, and reproduction in any medium, provided the original work is properly cited. 
purification of chromosome sections for proteomic analysis are used to study protein interactions on chromosomes [7-10]. One pitfall of these technologies is the challenge of purifying cognate histones (i.e., preserving the in vivo associated histones during isolation of chromatin). To overcome this pitfall, we have previously reported how to monitor and prevent dynamic exchange of histones during chromatin purification [11]. In vivo chemical cross-linking reagents, such as formaldehyde, can be used to prevent histone exchange during the purification of chromatin sections [12]. However, there is a balanced level of chemical cross-linking needed to trap protein-protein and protein-DNA interactions, while still allowing for the solubility of chromatin for purification and access of affinity reagents [12].

We have recently published a quantitative approach using I-DIRT, an isotopic labeling technique utilizing affinity purification and mass spectrometry, to measure levels of histone exchange in purified chromatin sections [11]. Here we describe a bioinformatic analysis, which expands on this published work, reporting the significance of proper cross-linking to capture histones with transcription activating PTMs during chromatin purification. In this work, we are able to gain new insights into the dynamic exchange of histones and post-translationally modified histones.

\section{Experimental Methods}

Detailed methods are described in Byrum et al. 2011. Briefly, Saccharomyces cerevisiae HTB1::TAP-HIS3 $B Y 4741$ (Open Biosystems) cells grown in isotopically light media and cells from an arginine auxotrophic strain (arg4::KAN BY4741, Open Biosystems) cultured in isotopically heavy media $\left({ }^{13} \mathrm{C}_{6}\right.$ arginine) were grown to midlog phase $\left(3.0 \times 10^{7}\right.$ cells $\left./ \mathrm{mL}\right)$ and cross-linked using either $0 \%, 0.05 \%, 0.25 \%$, or $1.25 \%$ formaldehyde (FA). The cells were harvested, mixed $1: 1$ by cell weight (isotopically light cells: heavy cells), and lysed under cryogenic conditions. The cell powder was resuspended in affinity purification buffer (20 mM HEPES pH 7.4, $300 \mathrm{mM} \mathrm{NaCl}, 0.1 \%$ tween-20, $2 \mathrm{mM} \mathrm{MgCl}_{2}$, and $1 \%$ Sigma fungal protease inhibitors) and the DNA sheared to $\sim 1 \mathrm{~kb}$ sections. Small chromatin sections containing TAP tagged $\mathrm{H} 2 \mathrm{~B}$ histones were affinity purified on IgGcoated Dynabeads and the eluted proteins were resolved with a 4-20\% Tris-Glycine gel. Following colloidal Coomassie-staining, histone gel bands were excised, trypsin digested, and tryptic peptides were subjected to tandem mass spectrometric analysis with a coupled Eksigent NanoLC-2D and Thermo LTQ-Orbitrap mass spectrometer [12]. The histone purification experiments were performed in triplicate.

The isotopically light and heavy arginine containing histone peptides were identified using a Mascot (version
2.2.03) database search. Peptide identification can be made with mass spectrometric database searching software other than Mascot with equivalent results. The search parameters included: precursor ion tolerance 10 ppm, fragment ion tolerance 0.6 Da, fixed modification of carbamidomethyl on cysteine, variable modification of oxidation on methionine and acetyl on lysine, and 2 missed cleavages possible with trypsin. The Mascot results were uploaded into Scaffold 3 (version 3.00.01) for viewing the proteins and peptide information. A false discovery rate of $1 \%$ was used as the cut off value for arginine containing histone peptides. The monoisotopic peak intensity (I) values for each arginine containing peptide were extracted using Qual Browser (version 2.0, Thermo). The percent light for each peptide was calculated as $I_{L} /\left(I_{L}+I_{H}\right)$. The average of all peptides identified for each percentage of cross-linking was calculated along with the standard error. The number of unique identified peptides was: bulk $\mathrm{H} 3(26,14,9$, and 8), H3K9acK14ac (7, 4, 8, and 8), bulk H4 (25, 8, 8, and $13)$, and H4K12acK16ac $(7,4,5$, and 3 ) for $0 \%, 0.05 \%$, $0.25 \%$ and $1.25 \%$ FA, respectively. Percent light peptide reported here differs from the Byrum et al report [11] as we have separated PTM containing and unmodified peptides in the current report.

\section{Results and Discussion}

The potential roles histone modifications play in regulating gene transcription and the recruitment of protein complexes to specific gene loci have made them attractive therapeutic targets for a variety of diseases including cancer. In order to preserve and study histone PTMs that occur on specific sites of chromatin, histone exchange must be prevented during the chromatin purification process. We previously utilized transient I-DIRT technology to investigate the level of chemical crosslinking with formaldehyde necessary to prevent histone exchange during chromatin purification [11]. Here, we have performed new bioinformatic analyses that reveal differential exchange rates for histones containing PTMs correlated to active gene transcription. As shown in Figure 1 and detailed in the Experimental Methods section, isotopically light histones were isolated via a TAP tag on $\mathrm{H} 2 \mathrm{~B}$ in the presence of an equivalent amount of isotopically heavy histones. The exchange of histones (i.e., the incorporation of isotopically heavy histones during the isolation of isotopically light histones) was followed with mass spectrometry.

Mascot analysis of the mass spectrometric data obtained from H2B-TAP cells treated with increasing amounts of formaldehyde identified lysine acetylation marks on histone H3 lysine 9 and lysine 14 (H3K9acK14ac) and histone H4 lysine 12 and lysine 16 (H4K12acK16ac). H3K9acK14ac and H4K12acK16ac are 


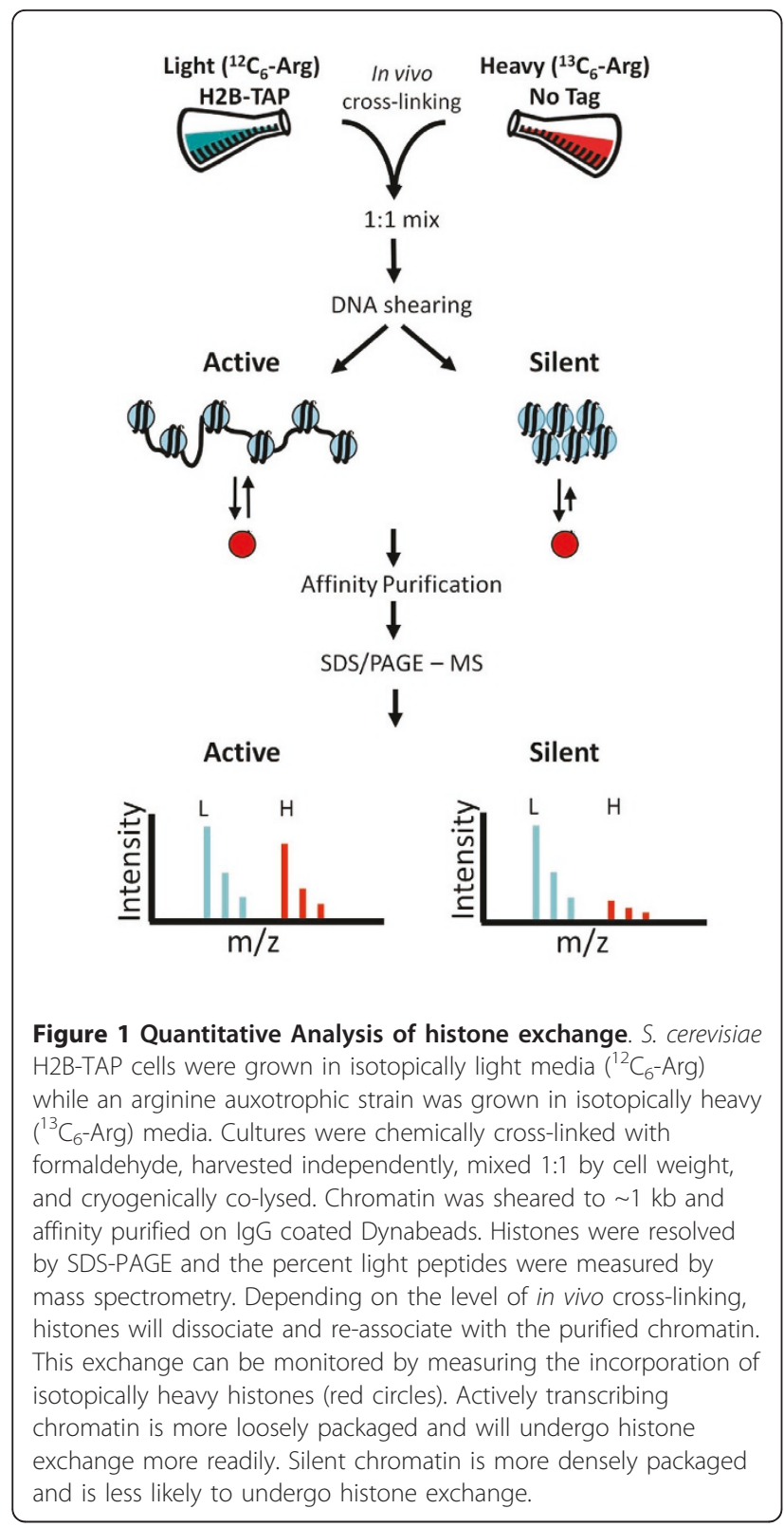

reported marks of active gene transcription, as is acetylation at many other histone lysines $[5,6,13,14]$. Representative mass spectra of bulk H3, H3K9acK14ac, bulk $\mathrm{H} 4$, and H4K12acK16ac peptides for each percentage of cross-linking are shown in Figure 2. The average percent light of all peptides identified for each histone is plotted in Figure 3. Percent light values approaching 100\% light peptides indicate minimal histone exchange during purification while those near $50 \%$ light peptides reflect rapid exchange. Peptides from the H2B-TAP control were $\sim 100 \%$ light at all formaldehyde concentrations tested. The reason that the H2B-TAP peptides are $\sim 100 \%$ light is that the TAP tagged version of $\mathrm{H} 2 \mathrm{~B}$ is only expressed in the strain grown in isotopically light media. This

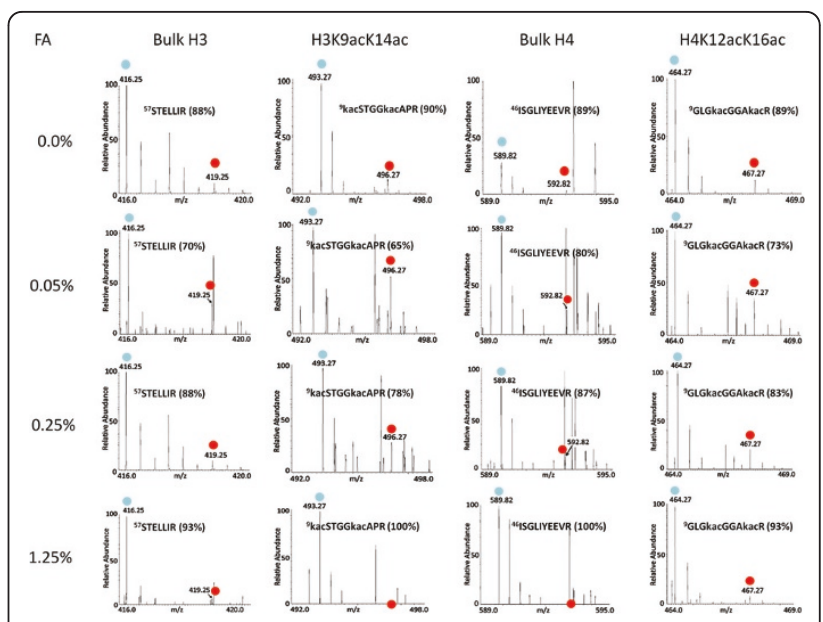

Figure 2 Mass spectra of PTM-containing histone peptides. Mass spectra were collected with an Orbitrap mass analyzer for doubly charged peptides from bulk histone H3, H3K9acK14ac, bulk histone $\mathrm{H} 4$, and $\mathrm{H} 4 \mathrm{~K} 12 \mathrm{acK} 16 \mathrm{ac}$. Blue circles indicate the isotopically light peak while red circles indicate the isotopically heavy peak. The percent isotopically light is shown in parentheses and in vivo formaldehyde (FA) cross-linking percentages are listed. 
isotopically light TAP tagged version of H2B migrates slower in SDS-PAGE due to the $\sim 20 \mathrm{kDa}$ molecular mass addition of the TAP tag; thus, excision of this band on the gel is exclusively for isotopically light H2BTAP as all other histones migrate further in the gel. Non-specific proteins co-enriching with H2B-TAP have $\sim 50 \%$ light peptides, reflecting the mixing of isotopically light and heavy cultures prior to purification. Without cross-linking, $\sim 10 \%$ histone exchange during purification was observed (Figure 3). As reported previously in Byrum et al 2011, mild cross-linking at 0.05\% actually increased the observed level of histone exchange during purification, which was not observed at elevated levels of cross-linking. We predict that cross-linking more readily stabilizes densely packaged areas of chromatin like heterochromatin, while leaving less densely packaged regions less stable. In accordance, as densely packaged chromatin becomes more heavily cross-linked, it becomes less represented in the analysis due to less efficient DNA shearing and solubility for purification. At a low level of formaldehyde (0.05\%), histone H3K9acK14ac peptides are closer to non-specific percent light indicating rapid histone exchange; however, bulk histone $\mathrm{H} 3$ is $\sim 80 \%$ light. This reveals that histones modified with activating transcription marks exchange more readily than histones without the transcription activating marks. This likely reflects the less densely packaged euchromatin that is more transcriptionally active. At $0.25 \%$ formaldehyde, acetylated histone H3K9acK14ac showed greater exchange compared with bulk H3; however, they both have increased percent light peptides indicating the minimization of exchange with increasing formaldehyde cross-linking. Bulk histone $\mathrm{H} 4$ and H4K12acK16ac had similar percentages of light peptides at $0.05 \%$ formaldehyde; however, acetylated $\mathrm{H} 4$ showed more exchange than bulk $\mathrm{H} 4$ at $0.25 \%$ formaldehyde. All bulk and acetylated peptides had $~ 100 \%$ light peptides at $1.25 \%$ formaldehyde, which indicated that the histones are minimally exchanged. Therefore, $1.25 \%$ formaldehyde is sufficient to prevent exchange of histones containing PTMs correlated to gene transcription during our purification of chromatin sections. The percent of formaldehyde cross-linking is specific for yeast synthetic media as other medias require different levels depending on their amine or cross-linking moiety content.

\section{Conclusions}

We have previously published the application of I-DIRT technology to determine the level of histone dissociation/ re-association during chromatin purification [11]. In this report, we have applied additional bioinformatic analyses to study the dynamics of exchange for histones containing transcription activating PTMs. As demonstrated in the histone exchange analysis shown in Figure 3, we show that chromatin marked for gene transcription is susceptible to the loss of histones during purification and therefore requires sufficient levels of in vivo chemical cross-linking to preserve the native chromatin composition. The technique reported in Byrum et al. 2011 and further analyzed here is relevant for a variety of genome-wide studies, and should be considered when preservation of in vivo chromatin content is essential for functional analyses, especially when examining transcriptional processes.

\section{Abbreviations}

I-DIRT: (isotopic differentiation of interactions as random or targeted); FA: (formaldehyde); ChIP: (chromatin immunoprecipitation); PTMs: (posttranslational modifications)

\section{Acknowledgements}

This work was funded by NIH R01DA025755, P20RR015569, P20RR016460 and F32GM093614.

\section{Author details}

'University of Arkansas for Medical Sciences, 4301 West Markham Street, Little Rock, Arkansas 72205, USA. ${ }^{2}$ Johns Hopkins School of Medicine, 855 North Wolfe Street, Baltimore, Maryland 21205, USA.

\section{Authors' contributions}

SDB carried out the experiments, data analysis, and drafted the manuscript. SDT and AJT conceived of the study and participated in its design and coordination. AJT helped to draft the manuscript. All authors read and approved the final manuscript.

\section{Competing interests}

The authors declare that they have no competing interests.

Received: 20 May 2011 Accepted: 7 July 2011 Published: 7 July 2011

\section{References}

1. Allis CD, Jenuwein T, Reinberg D, Caparros ML: Epigenetics Cold Spring Harbor Laboratory Press; 2006.

2. Suto RK, Clarkson MJ, Tremethick DJ, Luger K: Crystal structure of a nucleosome core particle containing the variant histone H2A.Z. Nature Structural Biology 2000, 7:1121-1124.

3. Taverna SD, Li H, Ruthenburg AJ, Allis CD, Patel DJ: How chromatinbinding modules interpret histone modifications: lessons from professional pocket pickers. Nat Struct Mol Biol 2007, 14:1025-1040.

4. Felsenfeld G, Groudine M: Controlling the double helix. Nature 2003, 421:448-453.

5. Dion MF, Altschuler SJ, Wu LF, Rando OJ: Genomic characterization reveals a simple histone $\mathrm{H} 4$ acetylation code. Proceedings of the National Academy of Sciences 2005, 102:5501-5506.

6. Luebben WR, Sharma N, Nyborg JK: Nucleosome eviction and activated transcription require p300 acetylation of histone $\mathrm{H} 3$ lysine 14. Proceedings of the National Academy of Sciences 2010, 107:19254-19259.

7. Tackett AJ, Dilworth DJ, Davey MJ, O'Donnell M, Aitchison JD, Rout MP, Chait BT: Proteomic and genomic characterization of chromatin complexes at a boundary. Journal of Cell Biology 2005, 169:35-47.

8. Dilworth DJ, Tackett AJ, Rogers RS, Yi EC, Christmas RH, Smith JJ, Siegel AF, Chait BT, Wozniak RW, Aitchison JD: The mobile nucleoporin Nup2p and chromatin-bound Prp20p function in endogenous NPC-mediated transcriptional control. Journal of Cell Biology 2005, 171:955-965.

9. Pokholok DK, Harbison CT, Levine S, Cole M, Hannett NM, Lee TI, Bell GW, Walker K, Rolfe PA, Herbolsheimer E, Zeitlinger J, Lewitter F, Gifford DK, Young RA: Genome-wide Map of Nucleosome Acetylation and Methylation in Yeast. Cell 2005, 122:517-527.

10. Déjardin J, Kingston RE: Purification of Proteins Associated with Specific Genomic Loci. Cell 2009, 136:175-186. 
11. Byrum S, Mackintosh SG, Edmondson RD, Cheung WL, Taverna SD, Tackett AJ: Quantitative Analysis of Histone Exchange during Chromatin Purification. Journal of Integrated OMICS 2011, 1:61-65.

12. Smart SK, Mackintosh SG, Edmondson RD, Taverna SD, Tackett AJ: Mapping the local protein interactome of the NuA3 histone acetyltransferase. Protein Science 2009, 18:1987-1997.

13. Shogren-Knaak M, Ishii H, Sun J-M, Pazin MJ, Davie JR, Peterson CL: Histone H4-K16 Acetylation Controls Chromatin Structure and Protein Interactions. Science 2006, 311:844-847.

14. Jin Q, Yu L-R, Wang L, Zhang Z, Kasper LH, Lee J-E, Wang C, Brindle PK, Dent SYR, Ge K: Distinct roles of GCN5/PCAF-mediated H3K9ac and CBP/ p300-mediated H3K18/27ac in nuclear receptor transactivation. EMBO J 2011, 30:249-262.

doi:10.1186/2043-9113-1-17

Cite this article as: Byrum et al:: Quantitative analysis of histone exchange for transcriptionally active chromatin. Journal of Clinical Bioinformatics 2011 1:17.

\section{Submit your next manuscript to BioMed Central} and take full advantage of:

- Convenient online submission

- Thorough peer review

- No space constraints or color figure charges

- Immediate publication on acceptance

- Inclusion in PubMed, CAS, Scopus and Google Scholar

- Research which is freely available for redistribution

Submit your manuscript at www.biomedcentral.com/submit 